\title{
ATIVIDADES EDUCATIVAS EMANCIPADORAS NA FORMAÇÃO DE PROFESSORES
}

\author{
Rafael Rossi ${ }^{1}$, Aline Santana Rossi ${ }^{2}$ \\ ${ }^{1}$ Doutorado e pós-doutorado em Educação pela Universidade Estadual Paulista - UNESP, Presidente Prudente, SP. \\ Docente na Faculdade de Educação e no Programa de Pós-Graduação em Educação - PPGEDU - da Universidade \\ Federal do Mato Grosso do Sul - UFMS, MS. ORCID iD: https://orcid.org/0000-0001-8544-3756. E-mail: \\ rafaelrossied@gmail.com \\ ${ }^{2}$ Mestre em Ensino de Ciências, pelo Programa de Pós-Graduação em Ensino de Ciências da Universidade Federal de \\ Mato Grosso do Sul - UFMS, MS. ORCID iD: https://orcid.org/0000-0002-8460-317X. E-mail: \\ alinesantanarossi@gmail.com
}

\section{RESUMO}

O presente artigo é instrumento por meio do qual problematizamos a discussão sobre as possibilidades de desenvolvimento de atividades educativas emancipadoras nos cursos de formação de professores a partir das reflexões de Tonet (2013), bem como a partir da pedagogia histórico-crítica. Elencamos quatro possíveis atividades desta natureza, levando em consideração a especificidade da dimensão educativa, as contradições que perpassam a educação no capitalismo, a distinção entre os interesses imediatos dos alunos empíricos e os interesses essenciais dos alunos concretos e, ainda, a reciprocidade dialética dos conteúdos escolares e as formas de ensino, com a prioridade ontológica dos conteúdos sobre as formas. Desse modo, tais atividades são propostas tendo como preocupação maior uma prática docente que preze pela promoção crítica do nível intelectual, científico, artístico e filosófico de professores e alunos. Trata-se de uma postura humanista, que defende a elaboração da crítica e a integridade humana contra todas as deturpações que esta forma de sociabilidade nos impõe.

Palavras-chave: Formação de Professores. Educação. Professor. Conhecimento.

\section{EMANCIPATING EDUCATIONAL ACTIVITIES IN TEACHER TRAINING}

\section{ABSTRACT}

This article is an instrument through which we problematize the discussion about the possibilities of developing emancipatory educational activities in teacher training courses based on Tonet's reflections (2013) and from de critical-historic pedagogy. We list four possible activities of this nature, taking into account the specificity of the educational dimension, the contradictions that permeate education in capitalism, the distinction between the immediate interests of the empirical students and the essential interests of the concrete students and, still, the dialectical reciprocity of the contents and forms of teaching, with the ontological priority of content over forms. Thus, such activities are proposed with the greatest concern for a teaching practice that values the critical promotion of the intellectual, scientific, artistic and philosophical level of teachers and students. It is a humanist stance, which defends the elaboration of criticism and human integrity against all the misrepresentations that this form of sociability imposes on us

Keywords: Teacher training. Education. Teacher. Knowledge.

\section{ACTIVIDADES EDUCATIVAS EMANCIPANTES EN LA FORMACIÓN DE PROFESORES}

\section{RESUMEN}

Este artículo es un instrumento a través del cual problematizamos la discusión sobre las posibilidades de desarrollar actividades educativas emancipadoras en cursos de capacitación docente basados en las reflexiones de Tonet (2013), así como de la pedagogía histórico-crítica. Enumeramos cuatro actividades posibles de esta naturaleza, teniendo en cuenta la especificidad de la dimensión educativa, las contradicciones que impregnan la educación en el capitalismo, la distinción entre los intereses inmediatos 
de los estudiantes empíricos y los intereses esenciales de los estudiantes concretos y, aún, la reciprocidad dialéctica de los contenidos. y formas de enseñanza, con la prioridad ontológica del contenido sobre las formas. Por lo tanto, tales actividades se proponen con la mayor preocupación por una práctica docente que valore la promoción crítica del nivel intelectual, científico, artístico y filosófico de profesores y estudiantes. Es una postura humanista, que defiende la elaboración de la crítica y la integridad humana contra todas las tergiversaciones que esta forma de sociabilidad nos impone.

Palabras clave: Formación de profesores. Educación. Profesor. Conocimiento.

\section{INTRODUÇÃO}

Neste texto discutimos a possibilidade de desenvolvimento de algumas atividades educativas emancipadoras nos cursos de formação de professores. O objetivo é contribuir com o debate sobre atividades educativas que prezem pela emancipação humana na formação de professores. Nossa base teórica e metodológica são as contribuições da ontologia marxiana e da pedagogia histórico-crítica.

Defendemos a tese de que, numa perspectiva humano-genérica, é necessária a realização de atividades educativas emancipadoras nos cursos de formação de professores levando em conta: 1) a especificidade da educação no processo de reprodução social, sem qualquer tipo de romantismo, idealismo, utopia, relativismo ou irracionalismo (LUKÁCS, 2013); 2) a relação educação e sociedade capitalista na atual sociedade (TONET, 2013); 3) a distinção entre aluno empírico e aluno concreto (SAVIANI, 2011) e; 4) a reciprocidade dialética entre conteúdos escolares e formas de ensino com a prioridade ontológica dos conteúdos.

Em primeiro lugar precisamos deixar claro a expressão "atividades educativas emancipadoras". Vivemos ainda na sociedade capitalista. Isto significa que existem classes sociais com interesses antagônicos. A classe dos capitalistas precisa se preocupar, acima de tudo, com a reprodução de seus lucros e a expansão de seus negócios e, por isso mesmo, apresentam interesses particulares. A enorme classe trabalhadora, por seu turno, possui como horizonte máximo a eliminação de toda e qualquer forma de exploração do homem pelo homem e, justamente em decorrência deste objetivo, ela é a única classe que apresenta uma perspectiva universal e emancipadora para todo o gênero humano e não apenas para algumas parcelas ou grupos (TONET, 2013).

Nesse sentido, em segundo lugar, precisamos compreender que o capital, isto é, as grandes corporações e grupos econômicos e financeiros, controlam e determinam os rumos de todos os complexos sociais (educação, arte, política, ideologia, etc.). Com efeito, no campo educacional, nesta sociedade capitalista não é uma possibilidade real e concreta a existência de uma "educação emancipadora". O que a realidade social coloca como possibilidade é o desenvolvimento de "atividades educativas emancipadoras", ou seja, atividades que permitam os indivíduos se conectarem com a emancipação humana. Emancipação humana, por sua vez, indica uma forma de sociedade para além do capital, na qual todos os indivíduos possam ter suas diversas necessidades plenamente atendidas e, também, possam se desenvolver livremente em todas as direções (artísticas, filosóficas, científicas, culturais, etc.) de acordo com os ensinamentos de Tonet (2013).

Neste texto propomos a reflexão de atividades educativas emancipadoras nos cursos de formação de professores que permitam, com base na história e na ciência, a partir dos interesses da classe trabalhadora, compreender a gênese e o funcionamento da sociedade capitalista, bem como os limites e as potencialidades que permeiam a dimensão educativa de modo a não supervalorizá-la de modo idealista.

Tal elaboração tem por base uma determinada articulação entre a teoria e a prática social. Aliás, este debate é decisivo na formação de professores. Em nosso entendimento, uma correta relação entre teoria e prática pode ser assimilada quando estudamos a perspectiva ontológica (LUKÁCS, 2013). Como Rossi e Rossi (2018) já demonstraram, na mesma linha de Lukács, o conhecimento teórico é a reprodução, no plano do pensamento, do movimento real do objeto, em sua essência, desenvolvimento e estruturação com a totalidade social. O objetivo da teoria é fornecer um conhecimento correto, o mais próximo possível, da essência do objeto. A prática, portanto, em sua dialética entre aparência e essência é o critério para a 
verificação dos avanços, lacunas ou desvios das teorias.

Nossa reflexão possui como norte as necessidades humanas de formação para além das análises que priorizam as demandas do mercado. Além disso, é preciso afirmar que não temos a ilusão de que todos os cursos de formação de professores podem abraçar plenamente o objetivo de contribuir com uma autêntica formação humano-genérica e não mercadológica. Nós ainda vivemos, nos educamos e nos tornamos professores no âmbito da sociedade capitalista. Isso significa que o objetivo máximo da produção social nesta forma de sociabilidade é a reprodução dos lucros a partir da exploração sobre o processo de trabalho (MÉSZÁROS, 2002).

É necessário sempre defender a ideia de que a "tarefa precípua dos professores é dominar e transmitir aos seus alunos o conhecimento científico, artístico e filosófico em suas formas mais desenvolvidas" (DUARTE, 2011, p. 138). Todavia, trata-se de uma tarefa de apropriação dos conhecimentos clássicos das ciências, das artes e da filosofia a partir dos interesses da classe trabalhadora como defende Tonet (2013).

\section{A ESPECIFICIDADE DA EDUCAÇÃO}

Para que os professores em seu processo formativo possam compreender a sua função social é da mais absoluta importância que eles conheçam e compreendam a particularidade da dimensão educacional. Nesse aspecto, os cursos de formação de professores precisam combater o irracionalismo, o romantismo, o idealismo e as utopias. Isto é necessário, pois é preciso analisar a educação como ela de fato é em sua essência, em seu movimento histórico, em suas articulações com a totalidade social. Para isso, não devemos deixar que nossos sonhos, desejos, vontades ou anseios atrapalhem o objetivo em traduzir o movimento real do objeto que estamos investigando (PAULO NETTO, 2011).

A educação não é a "arma mais poderosa capaz de transformar o mundo". A educação não é a "ponte de amor que conecta os indivíduos para o sonho da liberdade". A educação é uma dimensão social. Portanto, em primeiro lugar, devemos remontar o processo histórico de autoconstrução humana.

Os indivíduos não nascem já membros do gênero humano. Nós nascemos com potencialidade para nos tornarmos seres humanos. Se isto irá ocorrer ou não e, ainda, a qualidade deste processo formativo, são questões passíveis de entendimento em face do momento histórico e da totalidade social que estivermos analisando.

O ser humano surge na Terra a partir do momento em que começa a desempenhar atos de trabalho. Não estamos nos referindo ao trabalho assalariado, trabalho feudal ou trabalho escravo. $O$ trabalho a que estamos nos referindo é a interação orgânica da sociedade com a natureza para a produção dos meios de produção e de subsistência humanos. O trabalho não aparece entre os seres humanos de modo isolado, mas sim, em articulação recíproca com a comunicação e as relações sociais (LUKÁCS, 2013).

O trabalho é a única categoria que funda o ser social, ou seja, a humanidade, pois ele permite a produção de novas necessidades, novos atos de trabalho e novas dimensões sociais com funções distintas no processo de reprodução social. Entretanto, afirmar que o trabalho funda a humanidade não significa que ele a esgote! $A$ realidade social será formada pela determinação recíproca e ininterrupta entre os vários complexos sociais (educação, arte, ciência, filosofia, política, ideologia, trabalho, etc.), constituindo uma totalidade. A totalidade nesse aspecto é sempre fruto de um movimento histórico passado, apresentando o campo de limites e de possibilidades para nossa atuação no presente e, também, no que se refere às potencialidades e os obstáculos para a construção do futuro (LUKÁCS, 2013).

Com os atos de trabalho podemos observar uma articulação nova entre a consciência humana e a realidade. A partir de uma necessidade real e existente, a consciência passa a analisar os elementos da realidade objetiva e refletir sobre seus possíveis vínculos para que o fim previamente determinado possa ser alcançado (abater um animal para saciar a fome, por exemplo). Com isso, a partir da escolha da melhor estratégia, tem início o processo de objetivação, ou seja, de execução daquele projeto que a consciência elaborou. Desse modo, ao final dos atos de trabalho, os seres humanos puderam criar uma série de conhecimentos, habilidades e valores, por exemplo, que antes não possuíam. Isto é algo importantíssimo, pois estes conhecimentos poderão ser utilizados em outras situações distintas da situação original e, dessa forma, a reprodução das sociedades demonstrará uma complexificação crescente dos 
complexos sociais, das individualidades humanas e das próprias organizações sociais (LUKÁCS, 2013).

Estes conhecimentos, todavia, precisam ser apropriados pelas novas gerações para que elas possam continuar com o desenvolvimento humano. Este processo de transmissão e apropriação de conhecimentos perante as demandas de uma determinada totalidade social historicamente construída, constitui, com efeito, a especificidade da educação. Saviani (2011), nesse aspecto, afirma que:

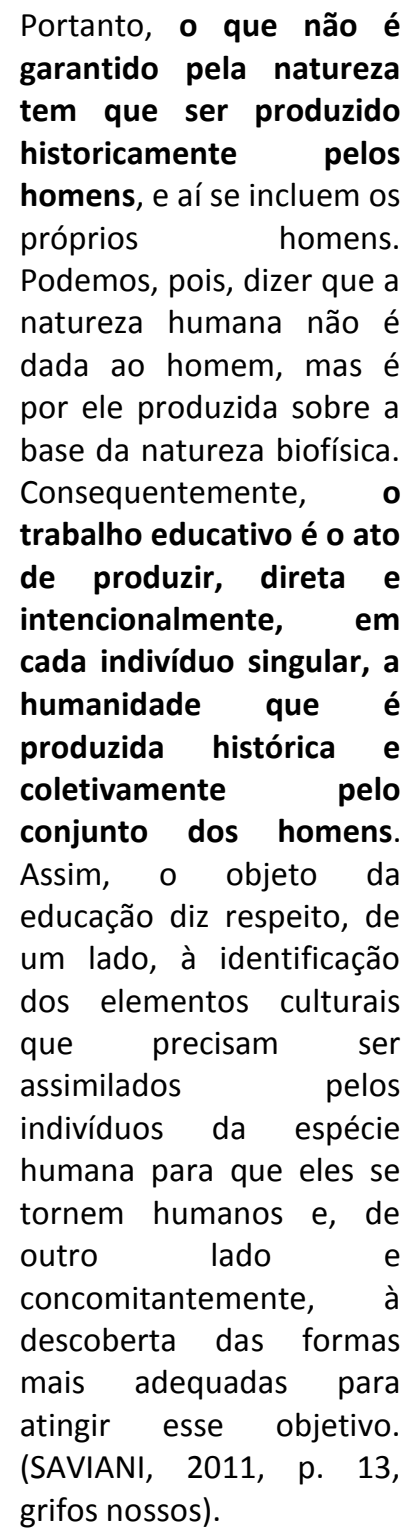

A análise empreendida por Saviani (2011) a respeito da particularidade da educação, em nosso entendimento, demonstra a importância de uma abordagem ontológica (isto é, respaldada na essência do processo histórico) na análise dos fenômenos investigados. Por outro lado, a partir do exame do processo de autoconstrução humana, ele extraiu elementos para explicitar a natureza mais íntima da educação. Tonet (2013) possui uma análise histórica e realista do fenômeno educativo:

A educação é, certamente, uma das dimensões de grande importância para a reprodução social. Ela existe desde os primeiros momentos da vida social, pois, ao contrário dos animais, os homens não nascem sabendo o que devem fazer para se reproduzir socialmente. A educação é condição imprescindível para que os seres humanos singulares se tornem, de fato, membros do gênero humano. Por isso eles precisam se apropriar do patrimônio - material e intelectual/cultural acumulado, em cada momento, pela humanidade contribuindo, ao mesmo tempo, para a construção deste mesmo patrimônio. A forma e a medida em que este processo de apropriação/efetivação se der nos permitirá aferir o estágio concreto em que se encontra o ser social. (TONET, 2013, p. 03-04, grifos nossos).

Portanto, uma importante atividade educativa emancipadora a ser realizada nos cursos de formação de professores é o entendimento concreto da educação. Se os alunos, que serão futuros professores, tiverem visões irracionais, românticas ou utópicas sobre a educação, tenderão a efetivar práticas espontaneístas, ingênuas e simplistas.

\section{A EDUCAÇÃO NA SOCIEDADE CAPITALISTA}

Os alunos e professores precisam compreender a gênese histórica da escola e, mais precisamente, a educação escolar no interior do processo de constituição e desenvolvimento da sociedade capitalista. Certamente a escola já existia antes do capitalismo. Entretanto ela era frequentada pelas classes que viviam da exploração do trabalho alheio. Com o capitalismo, algo novo ocorre nessa relação. A 
escola passa a ser o lócus por excelência do processo educativo na sociedade. Para a reprodução da sociedade burguesa é imprescindível que todos os seus cidadãos possam passar pelas escolas e terem um mínimo de apropriação dos rudimentos da cultura letrada, das ciências, das artes e das filosofias (SAVIANI, 2011).

No âmbito do capitalismo é impossível uma "educação emancipadora" em que todas as escolas e universidades possam permitir o livre desenvolvimento das individualidades intelectuais dos alunos e a plena socialização dos conhecimentos elaborados e acumulados ao longo da história. Por isso mesmo, concordamos com Tonet (2013) ao afirmar que o possível seria o desenvolvimento de atividades educativas emancipadoras, ou seja, atividades que prezem pelas ciências, pelas artes e pela filosofia a partir dos interesses da classe trabalhadora e que prezem pela defesa da emancipação humana. Importante compreender que:

No entanto, dada a
natureza específica -
contraditória - do ato que
funda a sociedade
burguesa, com todas as
suas consequências, é
possível, no interior desta
mesma sociedade,
desenvolver atividades
educativas que
contribuam para que a
classe trabalhadora e
integrantes de outras
classes tenham acesso ao
que há de mais elevado no
patrimônio acumulado
pela humanidade. De
forma limitada, mas é
possível. Pois uma coisa é
certa. Não basta, à classe
trabalhadora, ter acesso
aos conteúdos
tradicionais. A classe
trabalhadora tem
necessidade de um
conhecimento de caráter
revolucionário, isto é, de
um conhecimento que lhe
permita compreender o
conjunto do processo
histórico de tal modo que
ela se veja como sujeito
capaz de transformar
radicalmente o mundo.
Portanto, de um

conhecimento que esteja, pela sua própria configuração,

intimamente articulado com a transformação radical do mundo. Esta compreensão não lhe é, de modo nenhum, fornecida pelo simples acesso ao conhecimento sistematizado. Este simples acesso contribuirá, no máximo, para uma formação de alto nível, mas conservadora. É o que se pode observar cotidianamente. (TONET, 2013, p. 06, grifos nossos).

Precisamos combater os posicionamentos pós-modernos na formação de professores que desprezam os conhecimentos científicos e tentam desvalorizar a educação escolar. Nesse sentido, precisamos considerar sempre que:

Faz-se necessário, então, combater a tendência a formar professores para tudo quanto é coisa. Isso conduz a uma grande dispersão na formação do educador postulando-se que $o$ pedagogo e o professor precisam estudar, além da educação escolar, toda uma multiplicidade de modalidades educativas, o que leva a sobrecarregar os currículos formativos com uma grande quantidade de componentes

fragmentados que só podem ser superficialmente aprendidos.

Diferentemente disso penso que se formamos bem, isto é, de maneira sistemática, consistente e crítica os novos professores assegurandoIhes o domínio pleno da forma mais desenvolvida que é a forma escolar, as demais formas de educação serão compreendidas sem maiores dificuldades. Se 


\begin{abstract}
assim procedermos
estaremos evitando a descaracterização do processo formativo como se o curso pudesse dar conta de tudo e tudo tivesse o mesmo peso 0 que, aliás, é uma característica também da visão pós-moderna, em que tudo parece ter o mesmo peso, inclusive as modalidades de conhecimento nivelando ciência, senso comum, folclore, religião, bruxaria etc. Isto só pode se explicar pela consideração de que a forma social vigente atingiu sua fase de decadência quando não mais consegue se justificar racionalmente, restandoIhe apelar para elementos irracionais que se fazem presentes na visão dita pós-moderna. (SAVIANI, 2014, p. 29, grifos nossos).
\end{abstract}

Todavia, a sociedade burguesa é marcada por intensas contradições, por exemplo: ao mesmo tempo em que estimula o desenvolvimento de certas áreas da ciência, joga na ignorância e na miséria a maior parte da população mundial; ao mesmo tempo em que impulsiona a sofisticação dos conhecimentos da área médica, condena à dor e ao sofrimento todos aqueles que não podem pagar pelo acesso de tais tratamentos. O mesmo se passa com a educação escolar: por um lado, pela lógica do mercado e das classes dominantes, interessa que os trabalhadores se apropriem o mínimo possível das objetivações intelectuais das ciências, artes e filosofia. O conhecimento profundo, elaborado, sistematizado e crítico pode esclarecer sobre o modo de funcionamento desta forma de sociabilidade em suas raízes e isto, por sua vez, não é do interesse da burguesia.

A sociedade capitalista possui os germes de sua constituição no interior ainda da antiga sociedade feudal. O longo processo de transição do feudalismo ao capitalismo é constituído por uma série de dinâmicas que explicitam a superioridade civilizatória e social da sociedade burguesa frente àquela regida pela nobreza e pela Igreja.
A Revolução Industrial, nesse aspecto, foi algo extremamente inovador na história humana: pela primeira vez os seres humanos conseguiram superar os limites de sua própria força física. O capitalismo desenvolveu as forças produtivas, ou seja, a capacidade em transformar a natureza para o atendimento das necessidades sociais, de modo acentuadamente sofisticado. Podemos produzir, por exemplo, em nossos tempos, gêneros alimentícios em grau suficiente para alimentar o dobro da população mundial. A Revolução Francesa, por seu turno, também passou a demonstrar aos seres humanos que a história pode ser alterada significativamente. 0 poder do clero e da nobreza teve de se curvar perante o poder da burguesia, o poder do capital (PAULO NETTO; BRAZ, 2012).

A nova organização social dispensa a necessidade de súditos e coloca como exigência para o seu funcionamento a existência da cidadania moderna. Para ser cidadão é preciso que todos os indivíduos apresentem três características básicas: igualdade, propriedade e liberdade. Trabalhadores e capitalistas são iguais perante a lei. Trata-se de uma igualdade formal que, na prática, se conforma numa desigualdade real, uma desigualdade estrutural. Além disso, todos precisam ser proprietários: os capitalistas são proprietários dos meios de produção e do capital e os trabalhadores, por seu turno, são proprietários apenas da sua força de trabalho que precisa ser vendida em troca de um salário para garantir a sua sobrevivência. Por fim, capitalistas e trabalhadores são livres: os capitalistas são livres para utilizar seu capital na atividade que julgarem mais lucrativa e comprarem a força de trabalho daqueles trabalhadores que julgarem mais aptos e qualificados e os trabalhadores são livres para vender a sua força de trabalho aos capitalistas que estiverem dispostos a compra-la (TONET, 2005)

O lema dos revolucionários franceses de "liberdade, igualdade e fraternidade" demarca bem o horizonte e os limites da cidadania moderna. Na prática social, o que vivenciamos é a máxima "diga-me o teu poder aquisitivo e te direi até onde poderás ir e viver". O imenso desenvolvimento da ciência e da tecnologia, por exemplo, não estão livremente acessíveis para todos os indivíduos. A barreira do dinheiro seleciona aqueles que poderão usufruir das conquistas do capitalismo e aqueles que terão que sofrer nesta sociedade. 
Aqui reside uma questão importantíssima para os cursos de formação de professores: Trata-se de formar professores para a reprodução da sociedade capitalista em todas as suas desigualdades estruturais e barbáries como a pobreza, miséria, concentração de renda, devastação ambiental, etc.? Ou, por outro lado, trata-se de formar professores a partir dos interesses da classe trabalhadora que são, por sua vez, os únicos interesses que apresentam um panorama real para todas as necessidades da humanidade?

É importante lembrarmos que a enorme classe trabalhadora é marcada pelo processo de exploração. Todavia, os únicos trabalhadores que efetivam a transformação da natureza nos meios de produção e de subsistência da existência social (casas, pontes, estradas, alimentos, etc.) são os proletários. Isto é significativo para o debate educacional, pois as lutas por uma educação que permita o livre desenvolvimento e evolução intelectual de todos os seres humanos precisam contar com o entendimento teórico e com a atuação prática das lutas dos proletários rumo ao fim da exploração do homem pelo homem (TONET, 2020). Fundamental, neste aspecto, compreender que a luta da "classe trabalhadora pela sua emancipação e de toda a humanidade implica o conhecimento, o mais amplo e profundo possível, da realidade social a ser transformada" e, em razão disto nada menos "do que a verdade pode interessar à classe trabalhadora e como a verdade não é algo evidente, o trabalho sério e livre de sua busca impõe-se como uma tarefa inescapável, mesmo que tenha que ser muito dura" (TONET, 2010, p. 01).

A base desta sociedade se estrutura assim como o escravismo antigo e o feudalismo na exploração sobre o processo de trabalho. Todavia, trata-se de uma forma diferente de explorar o trabalho: a relação de assalariamento entra em cena. Com o trabalho assalariado o que ocorre é:

Com efeito, comprando a força de trabalho do proletário pelo seu valor, $\mathrm{o}$ capitalista tem o direito de dispor do seu valor de uso, isto é, de dispor da sua capacidade de trabalho, capacidade de movimentar os meios de produção. Mas a força de trabalho possui uma qualidade única, um traço que a distingue de todas as outras mercadorias: ela cria valor - ao ser utilizada, ela produz mais valor que o necessário para reproduzi-la, ela gera um valor superior ao que custa. E é justamente aí que se encontra o segredo da produção capitalista: o capitalista paga ao trabalhador o equivalente ao valor de troca da sua força de trabalho e não o valor criado por ela na sua utilização (uso) - e este último é maior que o primeiro. 0 capitalista compra a força de trabalho pelo seu valor de troca e se apropria de todo o seu valor de uso. (NETTO; BRAZ, 2012, p. 113)

Ou seja: os trabalhadores ao produzirem o conteúdo material da vida em sociedade (casas, portos, mercadorias, estradas, roupas, alimentos etc.) produzem um valor imensamente maior do que aquele que lhes é restituído sob a forma de salário. Está dada uma desigualdade estrutural nesta sociedade que, com uma série de mediações, irá impactar cada dimensão social, incluindo a educação escolar. Portanto, de um ponto de vista que se conecta positivamente com os interesses universais do gênero humano e, portanto, dos trabalhadores, é imprescindível, na formação de professores, investir esforços no desenvolvimento de atividades educativas emancipadoras que prezem pela compreensão histórica, científica e racional da dimensão educacional para não romantizá-la de modo idealista e, além disso, que permitam compreender a relação da educação com a sociedade capitalista. Não estamos afirmando que nas escolas e universidades nada pode ser realizado num caráter emancipatório. 0 que estamos argumentando é que a realidade social contemporânea coloca como possibilidade efetiva a promoção de atividades educativas emancipadoras. 


\section{ALUNO EMPÍRICO E SEUS INTERESSES IMEDIATOS; ALUNO CONCRETO E SEUS INTERESSES ESSENCIAIS}

A realidade natural e social não se revela plenamente ao nosso olhar ou à nossa percepção sensorial. A realidade é uma síntese histórica extremamente dinâmica entre aparência e essência. As aparências são as manifestações diversas e singulares do movimento da essência. A essência, por sua vez, são os aspectos de continuidade que marcam determinado objeto ou fenômeno. Por exemplo: a aparência da sociedade capitalista mudou enormemente desde o século XIX até este início de século XXI; contudo, a sua essência ainda permanece, ou seja, a exploração sobre o processo de trabalho. Os dados oficiais sobre a concentração de renda, as desigualdades sociais e a apropriação da riqueza socialmente produzida, comprovam este argumento (LUKÁCS, 2013).

Desse modo, é fundamental resgatar a distinção entre aluno empírico e aluno concreto, explicada por Saviani (2011):

O objetivo do processo
pedagógico éro
crescimento do aluno,
logo, seus interesses
devem necessariamente
ser levados em conta. O
problema é o seguinte:
quais são os interesses dos
alunos? De que aluno
estamos falando, do aluno
empírico ou do aluno
concreto? o aluno
empírico, o indivíduo
imediatamenter tem
observável,
determinadas sensações,
desejos e aspirações que
correspondem à sua
condição empírica
imediata. Estes desejos
não correspondem
necessariamente aos seus
interesses reais, definidos
pelas condições sociais
que o situam enquanto
indivíduo concreto. Em
contrapartida, conteúdos
que ela tende a rejeitar
são, no entanto, de seu
maior interesse enquanto
indivíduos concretos.
Assim, a ênfase nos
conteúdos instrumentais
não se desvincula da

realidade concreta dos alunos, pois é justamente a partir das condições concretas que se tenta captar por que e em que medida esses instrumentos são importantes. (SAVIANI, 2011, p. 71, grifos nossos)

Esta reflexão de Saviani (2011) é muito rica para medir a qualidade nos cursos de formação dos professores. Em primeiro lugar: qual o objetivo da atividade docente? É a promoção e desenvolvimento intelectual, científico, cultural, artístico e filosófico dos alunos. Em segundo lugar: qual a importância em trabalhar com a elevação e o enriquecimento dos alunos? A importância reside em trabalharmos com os seus interesses reais, concretos e não imediatos e espontâneos.

0 processo educativo precisa ser coordenado pelos professores para atingir esta meta de contribuir com o desenvolvimento humano-genérico dos alunos. Isto é necessário, pois se articula diretamente aos seus interesses concretos. Quem frequenta as escolas públicas, de modo geral? São os filhos da classe trabalhadora, ou seja, daquela classe social que, como já explicamos anteriormente, apenas possui a sua força de trabalho para ser vendida em troca de um salário. Os interesses imediatos dos trabalhadores são relacionados às necessidades de seu cotidiano: melhorar seu salário, pagar as contas, comprar determinado produto etc.

Entretanto, os interesses essenciais que correspondem à natureza mais íntima da classe trabalhadora é compreender em profundidade, com rigor, com conhecimentos científicos, artísticos e filosóficos o modo de funcionamento desta sociedade e eliminar por completo toda forma de exploração do homem pelo homem. Dessa maneira, para atingirmos os interesses concretos dos alunos concretos e não simplesmente dos alunos empíricos, é preciso desenvolver um processo educativo que possibilite que professores e alunos se apropriem das objetivações intelectuais mais desenvolvidas que a humanidade já produziu, numa abordagem crítica, isto é, numa abordagem que confronte estes conhecimentos com o movimento essencial da realidade enquanto totalidade.

De modo geral, os cursos de formação de professores invertem essa relação e trabalham 
com os interesses imediatos dos alunos empíricos, acreditando que, dessa maneira, estariam levando em conta os interesses essenciais dos alunos concretos. $O$ ensino não pode ficar refém do cotidiano, do superficial e das aparências. É necessário partir do cotidiano e do aparente e transmitir criticamente aquilo que de mais elevado a humanidade construiu no campo das ciências, das artes e da filosofia. Com a transmissão crítica destes conhecimentos elaborados os alunos poderão apreender as múltiplas articulações dos fenômenos estudados com a totalidade social e, com isso, poderão compreender de modo mais profundo, sistematizado e erudito a própria realidade para além de suas aparências. Em outras palavras:

A importância dos conteúdos escolares para o aumento do campo de escolhas dos indivíduos das novas gerações conecta-se ao fato de que esses conteúdos nada mais são do que experiência humana acumulada e sintetizada nas ciências, nas artes e na filosofia. Ao se apropriar desses conteúdos, os alunos estão incorporando à sua atividade, sua vida e sua individualidade, condensações da experiência social. Dessa maneira o indivíduo desenvolve a capacidade de agir guiado não apenas por percepções imediatas da realidade ao seu redor, mas pela compreensão das conexões não visíveis entre processos e fenômenos. Isso se aplica à compreensão do movimento tanto da natureza quanto da sociedade. Não é por acaso que os obscurantistas atacam as ciências da sociedade e também as ciências da natureza, além, é claro, da filosofia e das artes. (DUARTE, 2018, p. 144)

Os alunos em muitos casos não possuem ainda este entendimento. Pensemos, por exemplo, em tom de hipótese, que muitos alunos não considerem importante estudar o modo de funcionamento da sociedade feudal enquanto um conteúdo escolar na disciplina de história. Muitos alunos, categoricamente, poderiam afirmam: "De que me adianta na vida real saber sobre o feudalismo?" E muitos professores, por sua vez, poderiam ficam sem resposta. Do ponto de vista imediato, realmente não será necessário entender a relação de suserania e vassalagem típica da Idade Média. Contudo, do ponto de vista dos interesses dos alunos concretos é muito importante entendermos como o ser humano se forma enquanto um ser humano e, inclusive, o processo de constituição e destruição das sociedades passadas. O capitalismo não surgiu como uma "graça dos céus". A sociedade capitalista foi erguida num longo processo secular que teve como base as contradições inerentes ao movimento essencial da própria sociabilidade feudal. Se não compreendermos, com base na ciência e na história, por exemplo, como surgiu e como se estrutura a atual forma de sociabilidade, nossas análises e compreensões de mundo serão sempre epidérmicas, rasas e efêmeras.

Aqui reside a importância de compreender que, para a classe trabalhadora, interessa um conhecimento de caráter revolucionário. Isto significa que é sim muito relevante a apropriação e transmissão dos conhecimentos clássicos amealhados ao longo da história, todavia, é indispensável refletirmos sobre qual a concepção de mundo, de sociedade e de ser humano que estes conhecimentos foram transmitidos e apropriados. Por isso que:

Para evitar malentendidos, vale esclarecer, com precisão, o que se entende por conhecimento de caráter revolucionário. Não se trata de discutir a problemática do poder político e nem sequer de buscar politizar todo tipo de conhecimento. Afinal, não existe uma física, uma matemática ou uma química, etc., reacionária ou revolucionária. Mas, mesmo a física, a matemática ou a química são, elas mesmas, mediações para o conhecimento da natureza e estarão, ainda que de 
forma muito mediada, a serviço da construção de alguma forma de sociabilidade. Antes de ser físico, matemático ou químico, o sujeito é um ser humano, faz parte de uma sociedade concreta e também a ele dizem respeito os destinos da totalidade da sociedade. Independente da consciência desses cientistas, seu campo específico de atuação implica uma determinada concepção de mundo mais geral. Implícita ou explícita. Não é, pois, de modo nenhum, indiferente que um cientista da natureza tenha uma concepção de mundo revolucionária ou conservadora. Uma concepção revolucionária Ihe permitirá perceber a serviço de que e de quem está o conhecimento que ele produz! Além disto, uma concepção de mundo revolucionária permitirá que os conhecimentos produzidos nos diversos campos da ciência da natureza contribuam para a construção desta mesma concepção de mundo ao invés de ficarem confinados em suas esferas específicas e, muitas vezes, se colocarem lado a lado com crenças religiosas e/ou místicas e irracionalistas. (TONET, 2013, p. 06-07, grifos nossos)

Aqui chegamos a outra reflexão de suma relevância para a realização de atividades educativas emancipadoras nos cursos de formação de professores: a articulação entre conteúdos escolares e formas de ensino. Em muitos casos, de maneira geral, tende-se a supervalorizar as formas de ensino em detrimento dos conteúdos. Entender como se dá este equacionamento é um conditio sine qua non para a promoção de um processo educativo preocupado com os interesses essenciais dos alunos concretos.

\section{A PRIORIDADE ONTOLÓGICA DOS CONTEÚDOS ESCOLARES E A RECIPROCIDADE DIALÉTICA COM AS FORMAS DE ENSINO}

De modo geral há um incentivo desta forma de sociabilidade para desprezarmos a teoria e pensarmos em respostas rápidas para a prática educativa. Sem sombra de dúvida é importante refletirmos sobre as formas de ensino, todavia, esta reflexão se mostra mais precisa se tivermos a clareza do objetivo a atingir e, portanto, os conteúdos escolares a serem trabalhados.

Em nossa compreensão, os professores em seu processo de formação precisam ter condições de se apropriarem criticamente dos conhecimentos clássicos das ciências (sociais e naturais), das artes e da filosofia. Como já afirmamos, a crítica, nesta perspectiva, implica o confronto das teorias pedagógicas, por exemplo, com a essência do movimento real do conjunto do processo histórico (LUKÁCS, 2013).

A tarefa dos professores é justamente converter e pensar nas mediações didáticas necessárias para produzir os conteúdos escolares a serem transmitidos, tendo como preocupação e como norte geral às objetivações intelectuais mais elaboradas produzidas pelo gênero. Os conteúdos escolares possuem prioridade ontológica, com efeito, perante as formas de ensino. Isso significa que quando "atribuímos uma prioridade ontológica a determinada categoria com relação à outra, entendemos simplesmente o seguinte: a primeira pode existir sem a segunda, enquanto o inverso é ontologicamente impossível" (LUKÁCS, 2012, p. 307). Em nosso debate isto quer dizer que, no da formação de professores, as reflexões sobre as formas de ensinar precisam ser refletidas à luz dos conteúdos que se pretende transmitir - e, ainda, na concepção de tal processo educativo para atingir determinados objetivos conectados com a tarefa primordial de contribuir com a elevação do nível intelectual e crítico dos alunos.

Trata-se, então, da defesa dos conhecimentos históricos, científicos, artísticos e filosóficos clássicos, transmitidos a partir dos interesses da classe trabalhadora numa perspectiva revolucionária. Os alunos, que serão futuros professores, precisam se apropriar de uma teoria social que apresente a especificidade do conhecimento científico, artístico e filosófico. 
Estes conhecimentos avançam sobre as aparências do real e possibilitam nossa ampliação da concepção de mundo, de ser humano e de sociedade.

De modo extremamente rápido, podemos afirmar que a particularidade dos conhecimentos científicos é "capturar o objetivo ser-em-si de tudo aquilo que se relaciona com o trabalho e para comportar-se em relação aos fins e aos seus meios de maneira adequada ao seu ser-em-si" (LUKÁCS, 2013, p. 78). Isto é: à ciência cumpre fornecer um conhecimento aproximado mais fiel possível à essência da realidade objetiva. É nesse aspecto que a categoria da totalidade, enquanto uma categoria efetivamente existente na realidade mostra a sua importância na pesquisa educacional, por exemplo, já que a educação é uma totalidade própria, com dinâmicas inerentes ao seu movimento e, ao mesmo tempo, se relaciona com a totalidade do próprio conjunto social, pois:

O conhecimento, na medida em que é justo, isto é, total, reflete sempre um conjunto composto de totalidades unidas por laços orgânicos, mas só acede a ele por aproximação. Isto é assim, primeiro porque cada "todo" (cada círculo, para retomar a expressão de Hegel) que o conhecimento toma por objeto la estrutura econômica de tal país, por exemplo) faz ao mesmo tempo parte de uma totalidade ainda mais vasta, tanto histórica quanto teoricamente, o que significa que objetivamente sua totalidade é relativa. $E$ isto é assim ainda, porque o conhecimento que podemos ter da totalidade é necessariamente relativo, sendo apenas uma aproximação. É somente apreendendo correlações móveis, multilaterais e sempre mutáveis dos elementos, que chegaremos - nos limites de nossas possibilidades historicamente

determinadas - a cercar cada vez mais a realidade objetiva. (LUKÁCS, 1979, p. 240-241).

A arte, por sua vez, possibilita nos conectarmos com a trajetória do gênero humano de modo extremamente positivo, para além das alienações que imperam em nosso cotidiano. A autêntica obra de arte:

A verdadeira arte, portanto, sempre se aprofunda na busca daqueles momentos mais essenciais que se acham ocultos sob a superfície dos fenômenos, mas não representa esses momentos essenciais de maneira abstrata, ou seja, suprimindo os fenômenos ou contrapondo-os à essência; ao contrário, ela apreende exatamente aquele processo dialético pelo qual a essência se transforma em fenômeno, se revela no fenômeno, mas figurando ao mesmo tempo o momento no qual o fenômeno manifesta, na sua mobilidade, a sua própria essência. Por outro lado, esses momentos singulares não só contêm neles mesmos um movimento dialético, que os leva a se superarem

continuamente, mas se acham em relação uns aos outros numa permanente ação e reação mútua, constituindo momentos de um processo que se reproduz sem interrupção. A verdadeira arte, portanto, fornece sempre um quadro de conjunto da vida humana, representando-a no seu movimento, na sua evolução e desenvolvimento. (LUKÁCS, 2010, p. 26). 
A filosofia, por seu turno, reflete sobre as grandes questões e conflitos que marcam 0 gênero humano, problematizando as potencialidades para a construção do futuro, os obstáculos sociais no presente $\mathrm{e}$ as bases edificadas com o movimento histórico passado. A filosofia, dessa forma, "aprofunda as generalizações das ciências, antes de tudo, por estabelecer uma relação inseparável com 0 nascimento histórico e o destino do gênero humano, com a essência, o ser e o devir humanos" (LUKÁCS, 2013, p. 540).

$\mathrm{Em}$ todos os conhecimentos gerados pelas ciências, pelas artes e pela filosofia, a partir da crítica ontológica, é preciso distinguir aquelas ciências, obras de arte e filosofias que deturpam a essência humana e a rebaixam, daquelas que explicitam as contradições da dinâmica histórica em suas rupturas e continuidades. É imprescindível defendermos os conteúdos clássicos, a crítica ontológica e a defesa do ser humano contra todas as deturpações sociais que intentam o seu esfacelamento.

Este ponto é primordial na estruturação de atividades educativas emancipadoras nos cursos de formação de professores: o conhecimento clássico numa postura revolucionária que criticamente defende 0 humanismo, ou seja, "a integridade do homem contra todas as tendências que a atacam, a envilecem e a adulteram" (LUKÁCS, 2010, p. 19). Os conhecimentos clássicos com a crítica são fundamentais para uma "aproximação adequada da realidade inesgotável pelo conhecimento" que "postula o homem completo, que reencontrou sua totalidade", isto é, trata-se de um humanismo combativo, "que engaja os homens na luta, no conhecimento e na conquista do mundo e que trabalha - sendo ao mesmo tempo teoria e prática - para o nascimento do homem novo, com a totalidade humana reencontrada" (LUKÁCS, 1979, p. 251-252).

\section{CONCLUSÕES}

Com o presente texto abordamos o tema de atividades educativas emancipadoras que podem ser desenvolvidas nos cursos de formação de professores: 1) a compreensão histórica, científica e racional da dimensão educacional sem idealismos de qualquer tipo; 2) a relação da educação com a sociedade capitalista contemporânea e o correspondente esforço de compreensão da gênese e do funcionamento desta forma de sociabilidade; 3) a distinção entre os interesses aparentes e essenciais do processo formativo e intelectual dos alunos e; 4) a reciprocidade dialética entre conteúdos escolares e formas de ensino com a prioridade ontológica dos conteúdos.

Temos clareza, assim como Tonet (2013), de que no interior do capitalismo não será possível que todos os indivíduos se apropriem dos conhecimentos intelectuais clássicos construídos pela humanidade. Contudo, isto não inviabiliza em absoluto o desenvolvimento - com todas as inúmeras dificuldades que o cotidiano nos coloca - de atividades educativas emancipadoras, isto é, atividades no campo educativo que prezem pela integridade humana contra todas as deturpações irracionalistas e mercadológicas.

Tais elaborações possuem como fundamento a defesa do humanismo nos cursos de formação de professores. Um humanismo que não fica refém do cotidiano, que não se limita à superfície do real, que não se rende ao relativismo irracionalista e que não se curva perante as demandas egoístas do mercado. O humanismo combativo, de que nos fala Lukács (1979), tem como defesa a crítica e a transmissão do conhecimento científico, artístico e filosófico mais desenvolvidos que foram produzidos pelo gênero, no compromisso autêntico com a integridade humana contra as alienações que reinam em nossa sociedade.

\section{REFERÊNCIAS}

DUARTE, N. Luta de classes, educação e revolução. Germinal, Londrina, v. 3, n. 1, p. 128138, 2011.

DUARTE, N. O currículo em tempos de obscurantismo beligerante. Revista Espaço do Currículo, v. 11, n. 02, p. 139-145, 2018. Disponível

em:

https://periodicos.ufpb.br/index.php/rec/article/ view/ufpb.1983-1579.2018v2n11.39568. Acesso 01 mar. 2020. DOI: 10.22478/ufpb.19831579.2018v2n11.39568.

LUKÁCS, G. Existencialismo ou marxismo. São Paulo: Ed Ciências Humanas, 1979.

LUKÁCS, G. Introdução aos escritos estéticos de Marx e Engels. In: MARX, K.; ENGELS, F. Cultura, 
arte e literatura: textos escolhidos. São Paulo:

Expressão Popular, 2010. p. 11-38.

LUKÁCS, G. Para uma ontologia do ser social - I.

São Paulo: Boitempo: 2012.

LUKÁCS, G. Para uma ontologia do ser social - II.

São Paulo: Boitempo: 2013.

MÉSZÁROS, I. Para Além do Capital. São Paulo: Boitempo, 2002.

PAULO NETTO, J. Introdução ao estudo do método de Marx. São Paulo: Expressão Popular, 2011.

PAULO NETTO, J.; BRAZ, M. Economia política: uma introdução crítica. São Paulo: Cortez, 2012.

ROSSI, A. C. S.; ROSSI, R. Lukács, Ciência e Ontologia. In: JIMENEZ, S.; ALCANTARA, N. (Orgs.). Anuário Lukács 2018. São Paulo: Instituto Lukács, 2018. p. 107-122.

SAVIANI, D. Pedagogia histórico-crítica: Primeiras Aproximações. Campinas - SP: Autores Associados, 2011.

SAVIANI, D. A Pedagogia Histórico-Crítica. Revista Binacional Brasil Argentina, v. 03, n.02, p. 11-36, 2014.

TONET, I. Educação, cidadania e emancipação humana. ljuí: Unijuí, 2005.

TONET, I. Trabalho associado e revolução proletária. 2010. Disponível em: http://ivotonet.xp3.biz. Acesso em: 01 mar. 2020.

TONET, I. Atividades educativas emancipadoras. 2013. Disponível em: http://ivotonet.xp3.biz. Acesso em: 01 out. 2019. 